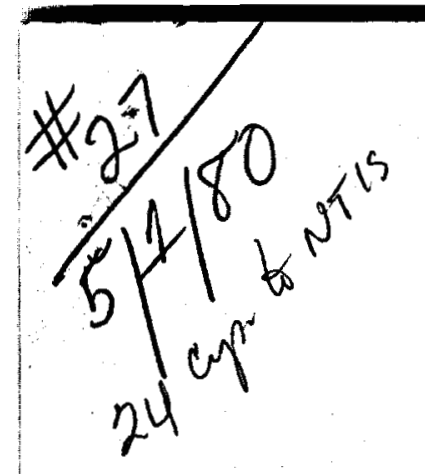

\title{
Studies of the dissolution of geothermal scale
}

\author{
S. B. Deutscher \\ D. M. Ross \\ R. Quong \\ J. E. Harrar
}

February 4, 1980 


\section{DISCLAIMER}

This report was prepared as an account of work sponsored by an agency of the United States Government. Neither the United States Government nor any agency Thereof, nor any of their employees, makes any warranty, express or implied, or assumes any legal liability or responsibility for the accuracy, completeness, or usefulness of any information, apparatus, product, or process disclosed, or represents that its use would not infringe privately owned rights. Reference herein to any specific commercial product, process, or service by trade name, trademark, manufacturer, or otherwise does not necessarily constitute or imply its endorsement, recommendation, or favoring by the United States Government or any agency thereof. The views and opinions of authors expressed herein do not necessarily state or reflect those of the United States Government or any agency thereof. 


\section{DISCLAIMER}

Portions of this document may be illegible in electronic image products. Images are produced from the best available original document. 
This report was prepared as an account of work sponsored by the United States Government. Neither the United States nor the United States Department of Energy, nor any of their employees, nor any of their contractors, subcontractors, or their employees, makes any warranty, express or implied, or assumes any legal liability or responsibility for the accuracy, completeness or usefulness of any information, apparatus, product or process disclosed, or represents that its use would not infringe privately owned rights.

Reference to a company or product name does not imply approval or recommendation of the product by the University of California or the U.S. Department of Energy to the exclusion of others that may be suitable.

Work performed under the auspices of the U.S. Department of Energy by the Lawrence Livermore Laboratory under Contract W-7405-Eng-48. 


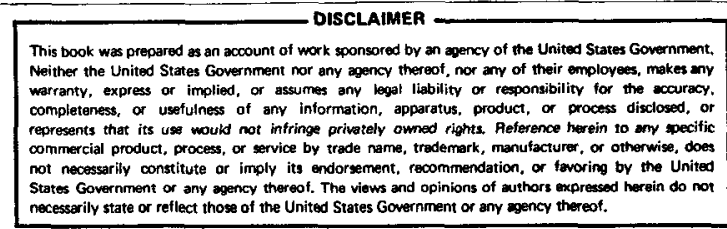

\title{
Studies of the dissolution of geothermal scale
}

\author{
S. B. Deutscher \\ D. M. Ross \\ R. Quong \\ J. E. Harrar
}

Manuscript date: February 4, 1980

\section{LAWRENCE LIVERMORE LABORATORY University of California $\bullet$ Livermore, California $\bullet 94550$}




\section{FOREWORD}

This work was performed at Lawrence Livermore Laboratory by laboratory personnel, with the exception of D. M. Ross, a student summer employee from the Department of Chemistry at Jackson State University, Jackson, Miss. 


\section{CONTENTS}

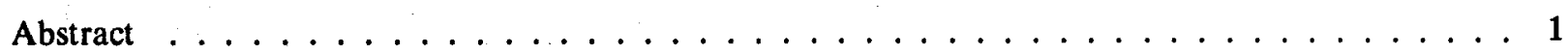

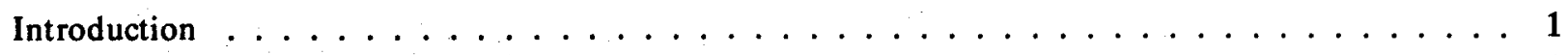

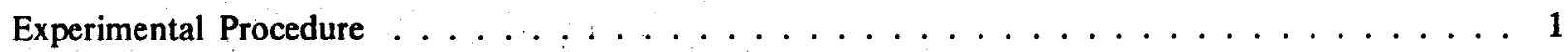

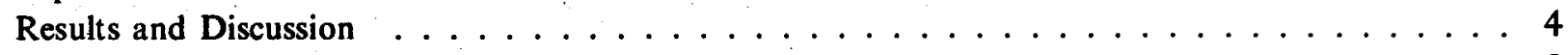

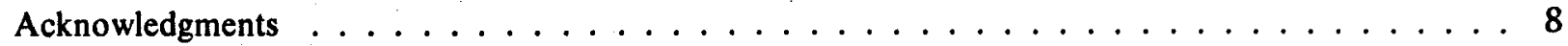

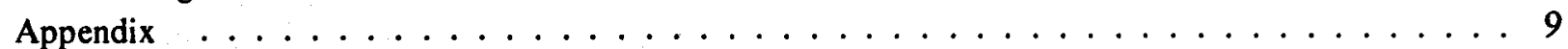




\title{
Studies of the dissolution of geothermal scale
}

\begin{abstract}
Samples of geothermal scale formed from Magmamax No. 1 and Woolsey No. 1 wells in the Imperial Valley, Calif., were exposed to concentrated and dilute solutions of common laboratory reagents. The time of exposure and temperature of the reagent were also varied. Several reagents easily dissolved significant amounts of the scale. An in situ test was performed with marginal success.

\section{INTRODUCTION}

One of the greatest obstacles to the development of the energy resources of the Salton Sea Geothermal Field-the high-temperature brines-is the formation of scale on process equipment as the brine cools. Until a scale-control method can be successfully demonstrated, both technically and operationally, the need to periodically descale geothermal plants will be a major disadvantage. For example, experience has shown that the removal of scale from the piping and components of the Geothermal Loop Experimental Facility (GLEF) of the San Diego Gas \& Electric Company is timeconsuming and costly.

Early work at the Sinclair No. 4 well ${ }^{1}$ demonstrated that concentrated acids significantly attacked in situ scales. Polished sections of scale formed on simulated turbine nozzles exposed to two-phase brine were treated with hydrochloric, sulfuric, and nitric acids. The results of one of these

end of the nozzle, consisted of a mixture of heavy metal sulfides and iron compounds dispersed in a silica matrix. The scale was exposed at room temperature to the acid solutions and considerable disintegration was produced.

Although chemical treatment may not effect complete dissolution of a scale, partial dissolution and/or softening may be sufficient to render the scale much easier to remove by mechanical techniques such as hydro-blasting, thus justifying the treatment economically. This investigation was aimed at determining whether dilute solutions of the most common chemical reagents could appreciably attack the scales of the Salton Sea Geothermal Field. The less concentrated solutions, if successful, would be less expensive; they would have the additional advantages of being less corrosive to metal plant structures and less dangerous to the personnel handling them.
\end{abstract} tests are shown in Fig. 1. This scale, formed near the

\section{EXPERIMENTAL PROCEDURE}

After the operation of the GLEF with Magmamax No. 1 brine for 1351 hours, ending in September 1978, six samples of scale were removed from various points in the plant as shown in Fig. 2. In March 1979, after 904 hours of operation with Woolsey No. 1 brine, five samples of scale were removed, the locations of which are also shown in Fig. 2. Also included in the dissolution experiments

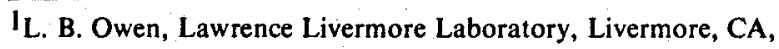
private communication (1978). was a sample of Magmamax No. 1 wellhead scale obtained in early 1978.

These samples represent scale deposited during two major periods of GLEF operation, and from two different wells whose brine chemistry is somewhat different. The appearance of the scales ranged from very wet and soft (V11) to very hard and dry (wellhead). The samples designated V11 Top and V11 were taken, respectively, from above and below the brine level of the second-stage separator. 


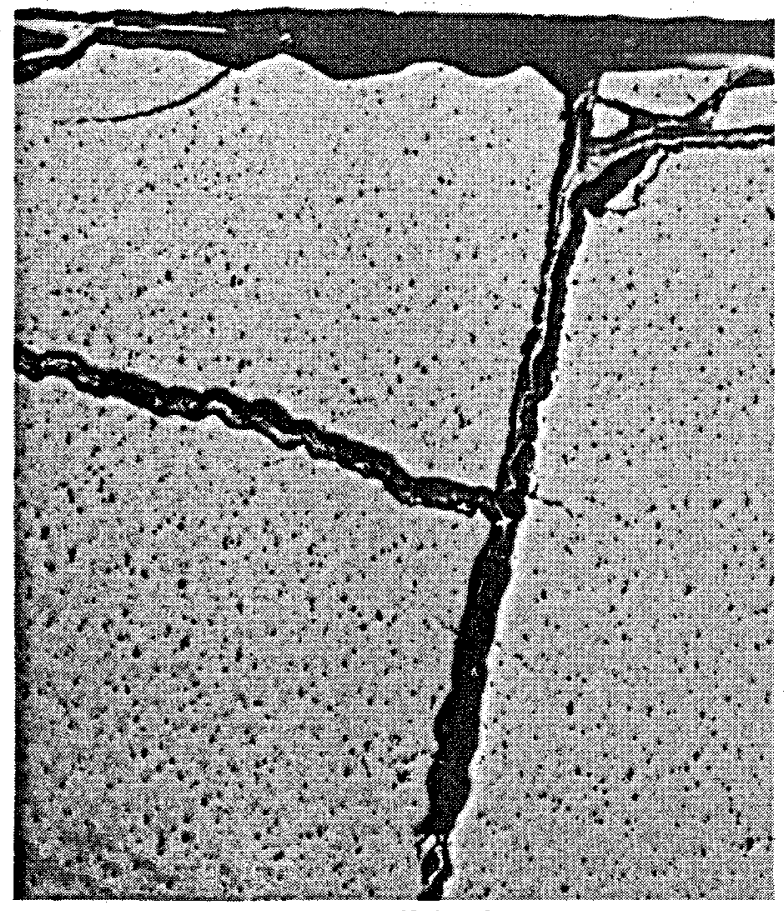

As polished

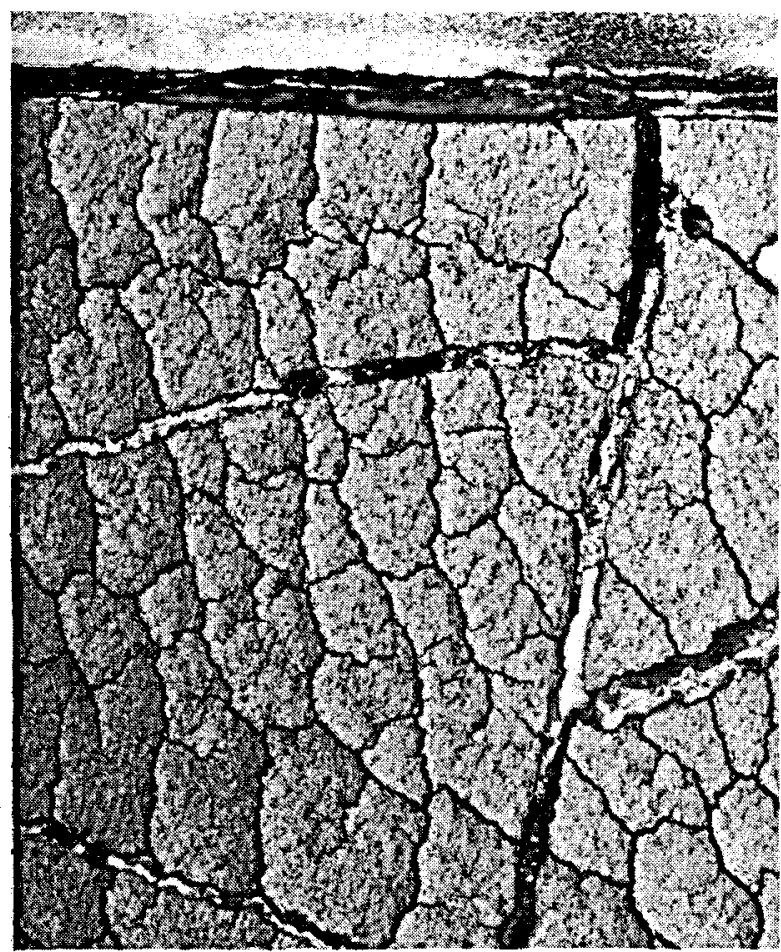

Treated with $6 M \mathrm{HCl}$ for $2-1 / 2$ minutes

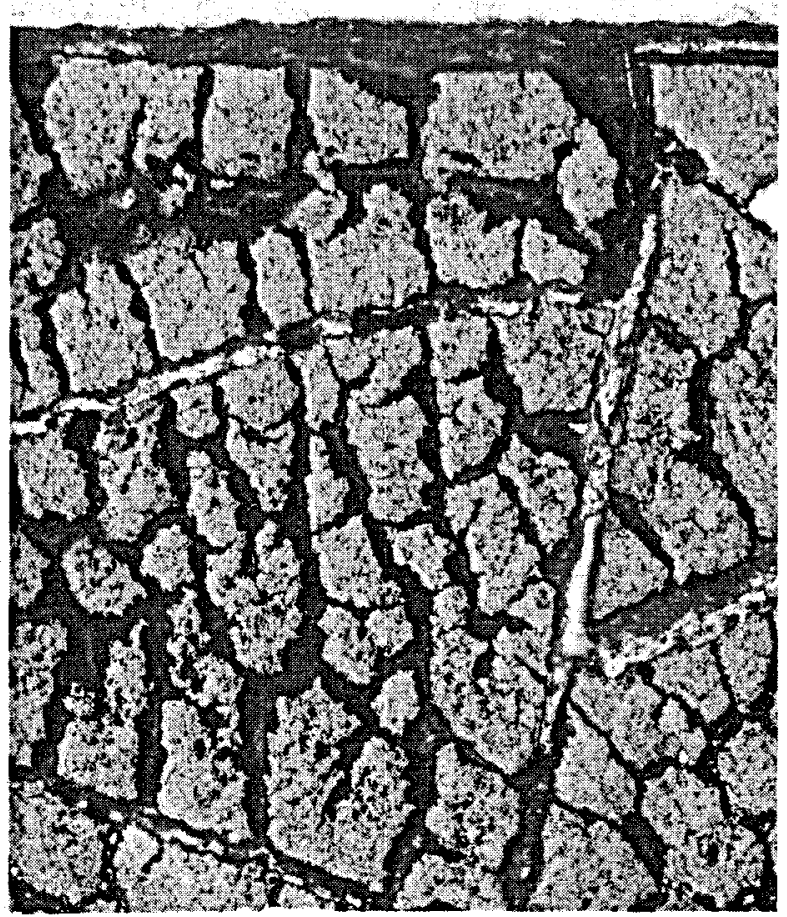

Treated with $6 \mathrm{M} \mathrm{HCl}$ for $2-1 / 2$ minutes, then $12 \mathrm{M} \mathrm{HCl}$ for 5 minutes

FIG. 1. Effect of concentrated hydrochloric acid on polished section of scale from Sinclair No. 4 brine (100X magnification). ${ }^{1}$ 


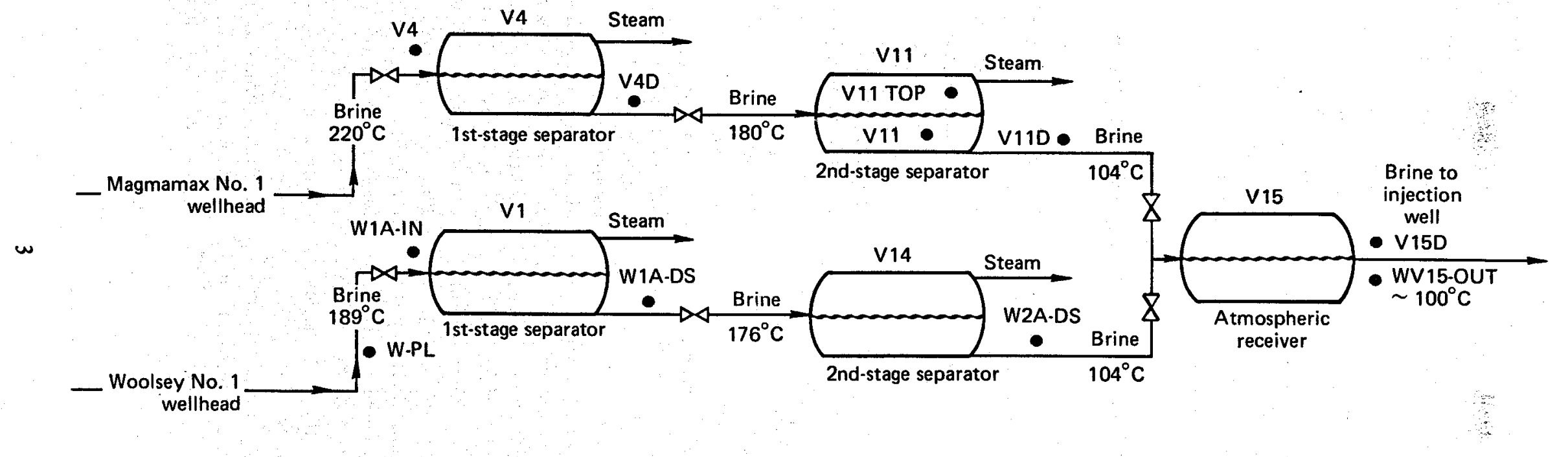

- Scale-sampling points

FIG. 2. Diagram of the Geothermal Loop Experimental Facility. 
The scale samples were rinsed, dried in a vacuum desiccator, and ground with a mortar and pestle. It was felt that ground samples, though they don't accurately represent an in-plant situation, were necessary to insure homogeneity and validity in comparisons of the various chemical treatments. As is well known, the chemical composition of a single scale can vary widely, especially in cross section.

A 1-g sample of the prepared scale was mixed with $100 \mathrm{ml}$ of the solution of interest, using a polyethylene-coated overhead stirrer. Stirring continued throughout the experiment. Solutions run at $80^{\circ} \mathrm{C}$ were allowed to warm before addition of the scale and were kept warm with hot plates during the experiment. After the allotted time had elapsed (1, 4 , or $24 \mathrm{~h}$ ) the mixtures were filtered through tared filter paper (Whatman No. 541). The filtrates were collected and the residues rinsed and allowed to dry for 2 days. A blank was run with each set by omitting the addition of the scale. The dried filter papers containing the residues were weighed, the amounts of dissolution calculated, and the residues together with the filtrates reserved for further analysis.

\section{RESULTS AND DISCUSSION}

The scales can be divided into three general types: those from the wellhead (or production line, in the case of the Woolsey scales), those from the first-stage separators, V4 and V1, and those from the second-stage separators, V11 and V14. (Scales from the V15 atmospheric receiver fit into the second-stage separator group.) The analyses of these scales are given in Tables 1 and 2. The results are typical: wellhead and production-line (W-PL) scales are primarily $\mathrm{PbS}$ with small amounts of $\mathrm{SiO}_{2}$; V4 and V1 scales (V4, V4D, W1A-IN, and W1A-DS) are mainly $\mathrm{SiO}_{2}$ and some PbS; V11, V14, and V15 scales (V11 TOP, V11, V11D, V15D, W2A-DS, and WV15-OUT) are mostly $\mathrm{SiO}_{2}$. Silica in all of the scales is amorphous.

The results of the dissolution experiments are given in Tables 3 and 4. Plots of the percentage of each scale dissolved by each reagent are given in the Appendix. The reagents were selected on the basis of our existing knowledge of the mineralogy of the scale deposited at the GLEF. The concentrations used would be considered "safe" in an in-plant situation. In addition to common laboratory solvents, a 2000-ppm solution of inhibited acrolein (2propenal) marketed as Magnatreat $M$ by Magna Corporation was tested on the V4 scales. Magnatreat $M$ is used to remove iron sulfide deposited at the formation surface in oil-field injection wells. In all cases it was less effective than water.

Although there are some discrepancies in the data, some general conclusions can be made as to the type of reagent tested that is best suited for dissolving a particular type of scale. For scales con- sisting predominately of amorphous silica, hot $\mathrm{NaOH}$ was effective. $\mathrm{NaOH}$ in combination with EDTA, a known complexing agent for metals, was even more effective than $\mathrm{NaOH}$ alone. At room temperature none of the reagents tested was effective, except perhaps for $0.1 M \mathrm{HF}$, which attacked the scale slightly. A more concentrated HF leach might have been beneficial, but would not be practical from safety considerations in an actual plant application. Not unexpectedly, $\mathrm{NaOH}$ and $\mathrm{NaOH}$ EDTA combinations had little or no effect on PbSor iron-rich scales.

$\mathrm{HCl}$ had some effect on the iron-rich scales, which consist partly of $\mathrm{Fe}_{3} \mathrm{O}_{4}$ or perhaps a complex iron-rich amorphous silica. Heat seemed to enhance the dissolution. Neither $\mathrm{HCl}$ nor $\mathrm{HNO}_{3}$, nor combinations, had much effect on silica-rich scales.

$\mathrm{HCl}$ alone was not sufficient to dissolve the PbS-rich scales. Addition of an oxidant, howevereither $\mathrm{H}_{2} \mathrm{O}_{2}$ or $\mathrm{HNO}_{3}$-enhanced the effectiveness considerably. The best combinations for dissolving $\mathrm{PbS}$-rich scales were $\mathrm{HNO}_{3}$ with $\mathrm{HF}$ or acetic acid (HAc) at $80^{\circ} \mathrm{C}$. Apparently they oxidize the sulfide, and formation of a lead acetate complex aids further dissolution. HF may help the overall dissolution by reacting with silica, which has been suggested as being the matrix material that cements the scales formed at high temperature.

An in situ scale-cleaning test based on these scale dissolution test results was conducted in the first-stage separator (wellhead conditions, hence $\mathrm{PbS}$ scale) of the LLL Niland test facility. Immediately following separator use, a solution of combined $0.5 \mathrm{M} \mathrm{HNO}_{3}$ and $0.5 \mathrm{M}$ HAc was injected 
TABLE 1. Composition (wt\%) of scales formed in the GLEF after operation with brine from Woolsey No. 1 and Magmamax No. 1 wells, as determined by $x$-ray fluorescence analysis and emission spectroscopy.

\begin{tabular}{|c|c|c|c|c|c|c|c|c|c|c|c|c|}
\hline \multirow[b]{2}{*}{ Element } & \multicolumn{5}{|c|}{ Woolsey No. 1 brine } & \multicolumn{7}{|c|}{ Magmamax No. 1 brine } \\
\hline & $\mathbf{W}-\mathbf{P L}$ & W1A-IN & W1A-DS & W2A-DS & WV15-OUT & Wellhead: & V4 & V4D & V11 TOP & v11 & V11D & $\mathbf{V 1 5}$ \\
\hline $\begin{array}{l}\text { Silicon } \\
\text { as } \mathrm{SiO}_{2}\end{array}$ & 0.15 & 33.0 & 40.4 & 78.7 & 52.6 & 4 & 25.8 & 23.6 & 66.4 & 57.2 & 70.3 & 63.8 \\
\hline Sulfur & 7.1 & 0.22 & 0.41 & 0.15 & 0.28 & 12 & 2.6 & 2.0 & 0.32 & 0.24 & 0.28 & 0.86 \\
\hline Chlorine ${ }^{a}$ & 0.12 & 2.6 & 2.0 & 1.1 & 3.4 & - & 3.5 & 2.5 & 0.89 & 4.8 & 3.2 & 3.8 \\
\hline Potassium $^{2}$ & 0.08 & 1.6 & 1.1 & 0.76 & 2.0 & - & 1.6 & 1.7 & 0.58 & 1.09 & 0.96 & 0.89 \\
\hline Calcium $^{\mathrm{a}}$ & 0.20 & 3.3 & 1.6 & 1.1 & 4.5 & 0.2 & 3.6 & 2.4 & 1.08 & 2.9 & 4.4 & 1.9 \\
\hline Titanium ${ }^{2}$ & - & - & - & - & - & 0.03 & - & - & 0.01 & 0.008 & 0.07 & 0.08 \\
\hline Manganese $^{a}$ & 0,41 & 2.0 & 2.5 & 0.33 & 0.37 & 0.03 & 1.2 & 1.1 & 0.67 & 0.16 & 0.65 & 0.06 \\
\hline Iron $^{2}$ & $\geqslant 8.2$ & $\geqslant 13$ & $\geq 14$ & 2.0 & 1.8 & 0.7 & 17.7 & 11.6 & 12.5 & 0.88 & 0.68 & 0.92 \\
\hline Coppex $^{2}$ & 0.25 & 0.42 & 0.43 & 0.08 & 0.18 & 0.02 & 0.28 & 0.10 & 0.38 & 0.05 & 0.04 & 0.32 \\
\hline Zinc $^{n}$ & 0.11 & 0.11 & 0.13 & 0.12 & 0.13 & 0.07 & 1.02 & 0.26 & 0.17 & 0.07 & 0.15 & 0.06 \\
\hline Rubidium $^{\mathbf{a}}$ & 0.10 & 0.02 & 0.01 & 0.008 & 0.01 & - & - & - & - & 0.004 & 0.004 & 0.005 \\
\hline Strontium ${ }^{a}$ & .00 & 0.07 & 0.03 & 0.05 & 0.09 & Trace & 0.11 & 0.07 & 0.02 & 0.05 & 0.04 & 0.04 \\
\hline Silver $^{a}$ & - & - & - & - & - & 0.34 & 0.12 & 0.09 & 0.01 & 0.01 & 0.01 & 0.009 \\
\hline Antimony ${ }^{2}$ & - & - & - & - & - & Trace & 0.04 & 0.01 & 0.12 & 0.01 & 0.005 & 0.006 \\
\hline Barium $^{b}$ & 0.1 & 0.15 & 0.2 & 0.6 & 0.4 & - & 0.1 & 0.05 & 0.03 & 0.02 & 0.3 & 0.3 \\
\hline Lead $^{\mathbf{a}}$ & $\geqslant 20.0$ & 1.0 & 2.3 & 0.12 & 0.40 & $\sim 76$ & 15.1 & 16.0 & 3.6 & 0.50 & 0.48 & 0.32 \\
\hline Arsenic $^{\mathrm{a}}$ & 0.19 & 0.09 & 0.12 & 0.05 & 0.02 & - & - & - & $<0.2$ & $<0.04$ & $<0.01$ & $\leqslant 0.01$ \\
\hline Sodium ${ }^{b}$ & 0.2 & 5 & 2 & $\mathbf{1}$ & .5 & - & 5 & 2 & 2 & 10 & 10 & 10 \\
\hline Aluminum ${ }^{b}$ & 0.1 & 0.4 & 0.5 & 0.15 & 0.05 & - & 1.0 & 0.05 & 0.5 & 0.03 & 0.05 & 0.05 \\
\hline Magnesium $^{\mathbf{b}}$ & 0.04 & 0.5 & 0.5 & 0.04 & 0.02 & - & 1.0 & 0.04 & 0.3 & 0.04 & 0.03 & 0.01 \\
\hline Boron $^{\text {b }}$ & 0.005 & 0.04 & 0.04 & 0.05 & 0.04 & - & 0.03 & 0.05 & 0.02 & 0.05 & 0.07 & 0.07 \\
\hline Beryllium $^{\mathbf{b}}$ & 0.001 & 0.008 & 0.015 & 0.015 & 0.004 & - & 0.01 & 0.008 & 0.005 & 0.005 & 0.005 & 0.005 \\
\hline Molybdenum $^{\text {b }}$ & 0.01 & 0.01 & 0.01 & $\mathrm{nd}^{\mathrm{c}}(<0.003)$ & nd $(<0.003)$ & - & 0.01 & 0.003 & 0.003 & nd $(<0.003)$ & nd $(<0.003)$ & nd $(<0.003)$ \\
\hline Zirconium $^{\mathbf{b}}$ & nd $(<0.001)$ & 0.01 & 0.01 & nd $(<0.001)$ & nd $(<0.001)$ & - & $\leqslant 0.01$ & $\leqslant 0.005$ & $\leqslant 0.005$ & nd $(<0.001)$ & nd $(<0.001)$ & nd $(<0.001)$ \\
\hline Chromium $^{b}$ & 0.01 & $\leqslant 0.003$ & $<0.003$ & $\leqslant 0.003$ & $\$ 0.003$ & - & 0.003 & nd $(<0.003)$ & 0.003 & nd $(<0.003)$ & nd $(<0.003)$ & nd $(<0.003)$ \\
\hline Cobalt ${ }^{\mathbf{b}}$ & 0.003 & 0.001 & 0.001 & nd $(<0.001)$ & nd $(<0.001)$ & - & 0.01 & 0.001 & 0.001 & $\leqslant 0.0003$ & $\leqslant 0.0003$ & $\leqslant 0.003$ \\
\hline Nickel $^{b}$ & 0.01 & 0.003 & 0.005 & 0.0005 & 0.0005 & - & 0.01 & 0.01 & 0.01 & nd $(<0.0003)$ & 0.0003 & 0.0003 \\
\hline Cadmium $^{b}$ & nd $(<0.01)$ & nd $(<0.01)$ & nd $(<0.01)$ & nd $(<0.01)$ & nd $(<0.01)$ & - & $0.005^{a}$ & nd $(<0.01)$ & nd $(<0.01)$ & nd $(<0.01)$ & nd $(<0.01)$ & nd $(<0.01)$ \\
\hline
\end{tabular}

\footnotetext{
a By x-ray fluorescence analysis.

by emission spectroscopy.
}

Not detected. Elements not detected in any sample, bismuth $(<0.003)$, niobium $(<0.003)$, tin $(<0.003)$, and vanadium $(<0.001)$. 
TABLE 2. Composition of scales formed in the GLEF after operation with brine from Woolsey No. 1 and Magmamax No. 1 wells, as determined by $x$-ray diffraction analysis.

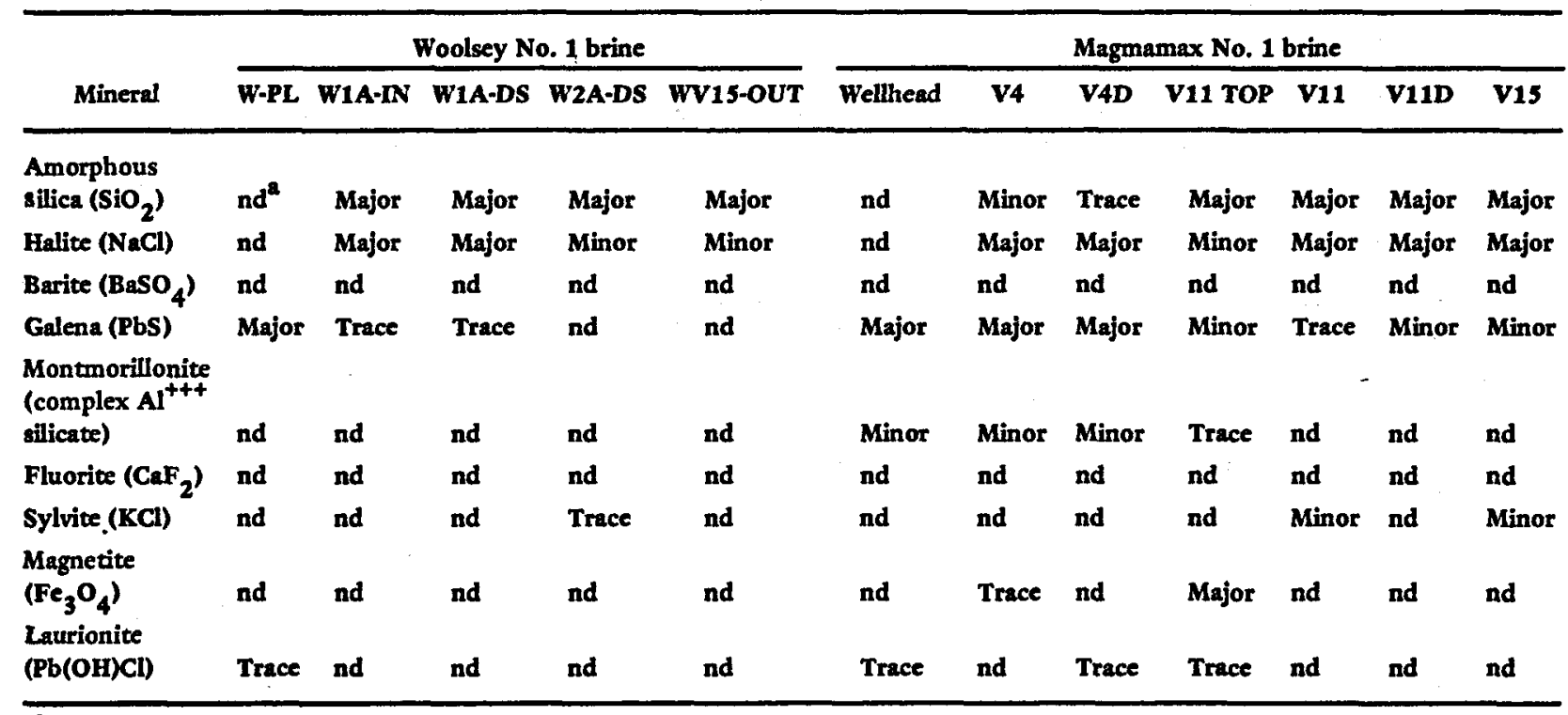

TABLE 3. Results (\% scale dissolved) of the dissolution tests on Woolsey No. 1 scales.

\begin{tabular}{|c|c|c|c|c|c|c|c|}
\hline \multirow[b]{2}{*}{ Solvent } & \multirow{2}{*}{$\begin{array}{c}\text { Time, } \\
\text { h }\end{array}$} & \multirow{2}{*}{$\begin{array}{c}\text { Temperature, } \\
{ }^{\circ} \mathbf{C}\end{array}$} & \multicolumn{5}{|c|}{ Scale } \\
\hline & & & W-PL & W1A-IN & W1A-DS & W2A-DS & WV15-OUT \\
\hline \multirow{3}{*}{$\begin{array}{c}0.2 \mathrm{MNO}_{3} \\
+ \\
0.5 \mathrm{M} \mathrm{HCl}\end{array}$} & 1 & 25 & 11.4 & 28.9 & 12.1 & 14.5 & 45.3 \\
\hline & 24 & 25 & 24.6 & 49.2 & 32.5 & 16.2 & 47.8 \\
\hline & 4 & 80 & 45.5 & 57.1 & 45.6 & 15.8 & 50.2 \\
\hline \multirow{3}{*}{$\begin{array}{c}0.05 M \text { EDTA } \\
+ \\
0.5 M \text { NaOH }\end{array}$} & 1 & 25 & 9.3 & 16.9 & 0.1 & 11.6 & 47.0 \\
\hline & 24 & 25 & 18.2 & 19.5 & 4.4 & 18.0 & 52.1 \\
\hline & 4 & 80 & 12.3 & 23.0 & 5.4 & 49.4 & 85.9 \\
\hline \multirow[t]{3}{*}{$0.5 M \mathrm{HCl}$} & 1 & 25 & 20.6 & 37.3 & 19.2 & 15.2 & 46.4 \\
\hline & 24 & 25 & 25.3 & 53.2 & 46.3 & 16.4 & 47.8 \\
\hline & 4 & 80 & 38.1 & 59.4 & 48.0 & 17.6 & 67.1 \\
\hline \multirow{3}{*}{$0.5 \mathrm{M} \mathrm{NaOH}$} & 1 & 25 & 11.8 & 17.2 & 3.4 & 14.0 & 42.6 \\
\hline & 24 & 25 & 11.0 & 17.5 & 3.2 & 6.2 & 44.0 \\
\hline & 4 & 80 & 15.4 & 20.0 & 7.7 & 55.7 & 58.4 \\
\hline \multirow[t]{3}{*}{$0.1 M$ HF } & 1 & 25 & 15.7 & 54.4 & 40.8 & 25.5 & - \\
\hline & 24 & 25 & 23.4 & 57.1 & 33.5 & 27.2 & 62.1 \\
\hline & 4 & 80 & 24.1 & 65.0 & 28.9 & 29.8 & 64.0 \\
\hline \multirow{3}{*}{$\begin{array}{c}0.1 M \mathrm{HF} \\
+ \\
0.5 M \mathrm{HNO}_{3}\end{array}$} & 1 & 25 & 23.1 & 59.5 & 43.1 & 24.9 & 62.2 \\
\hline & 24 & 25 & 38.7 & 76.9 & 63.6 & 28.4 & 65.4 \\
\hline & 4 & 80 & 87.9 & - & 59.9 & 26.3 & 63.9 \\
\hline \multirow{3}{*}{$\begin{array}{c}0.5 \mathrm{MHNO} \\
+ \\
0.5 \mathrm{MAc}\end{array}$} & 1 & 25 & 10.9 & 27.5 & 10.2 & 12.8 & 46.0 \\
\hline & 24 & 25 & 21.4 & 43.5 & 22.6 & 12.7 & 48.8 \\
\hline & 4 & 80 & 78.4 & 50.0 & 37.0 & 17.7 & 48.9 \\
\hline \multirow{2}{*}{$\underset{+}{0.13 M \mathrm{H}_{2} \mathrm{O}_{2}}$} & 1 & 25 & 12.5 & 25.8 & 10.0 & 13.3 & 47.5 \\
\hline & 24 & 25 & 24.2 & 42.3 & 23.6 & 15.9 & 48.4 \\
\hline $0.5 M \mathrm{HCl}$ & 4 & 80 & 41.8 & 58.2 & 44.5 & 19.5 & 45.4 \\
\hline \multirow{3}{*}{$\mathbf{H}_{2} \mathbf{O}$} & $\mathbf{1}$ & 25 & 1.8 & 12.4 & 1.8 & 12.0 & 44.6 \\
\hline & 24 & 25 & 2.7 & 19.3 & 2.2 & 11.9 & 44.3 \\
\hline & 4 & 80 & 3.8 & 20.5 & 3.6 & 12.6 & 45.8 \\
\hline
\end{tabular}


TABLE 4. Results (\% scale dissolved) of the dissolution tests on Magmamax No. 1 scales.

\begin{tabular}{|c|c|c|c|c|c|c|c|c|c|}
\hline \multirow[b]{2}{*}{ Solvent } & \multirow{2}{*}{$\begin{array}{c}\text { Time, } \\
\text { h }\end{array}$} & \multirow{2}{*}{$\begin{array}{l}\text { Temperature, } \\
{ }^{\circ} \mathrm{C}\end{array}$} & \multicolumn{7}{|c|}{ Scale } \\
\hline & & & V15D & V4D & V11 TOP & V11D & V11 & V4 & Wellhead \\
\hline \multirow{2}{*}{$\begin{array}{c}0.2 M \mathrm{HNO}_{3} \\
+\end{array}$} & 1 & 25 & 19.2 & 35.3 & 12.3 & 29.3 & 22.3 & 39.4 & 13.6 \\
\hline & 24 & 25 & 24.7 & 58.7 & 11.5 & - & 29.4 & 58.0 & 10.4 \\
\hline $0.1 M \mathrm{HCl}$ & 1 & 80 & 20.7 & 58.8 & 21.0 & 28.0 & 24.3 & 61.3 & 11.0 \\
\hline \multirow{2}{*}{$\begin{array}{c}\text { 0.05M EDTA } \\
+\end{array}$} & 1 & 25 & 23.0 & 10.8 & 7.9 & 27.0 & 26.2 & 15.9 & 6.5 \\
\hline & 24 & 25 & 23.3 & 19.8 & 10.6 & 33.4 & 24.8 & 22.2 & 9.01 \\
\hline $0.5 M \mathrm{NaOH}$ & 1 & 80 & 68.4 & 17.7 & 10.9 & 56.5 & 29.8 & 19.0 & 4.6 \\
\hline \multirow[t]{3}{*}{$0.5 \mathrm{M} \mathrm{HCl}$} & 1 & 25 & 19.4 & 25.1 & 8.7 & 29.3 & 23.8 & 31.5 & 4.9 \\
\hline & 24 & 25 & 21.7 & 56.3 & 19.4 & 32.2 & 26.7 & 58.7 & 9.7 \\
\hline & $\mathbf{1}$ & 80 & 53.8 & 29.6 & 24.3 & 30.1 & 25.5 & 60.7 & 10.1 \\
\hline \multirow[t]{3}{*}{$0.5 M \mathrm{NaOH}$} & $\mathbf{1}$ & 25 & 20.6 & 8.0 & 7.9 & 24.0 & 24.8 & 14.8 & 3.4 \\
\hline & 24 & 25 & 17.3 & 9.5 & 5.4 & 18.7 & 18.6 & 15.6 & 3.8 \\
\hline & 1 & 80 & 62.3 & 10.5 & 7.9 & 26.9 & 22.2 & 16.3 & - \\
\hline \multirow[t]{3}{*}{$0.1 M$ HF } & 1 & 25 & 33.1 & 32.5 & 14.9 & 31.0 & 27.5 & 32.4 & 7.7 \\
\hline & 24 & 25 & 34.8 & 40.5 & 27.8 & 38.5 & 34.2 & 46.7 & 11.9 \\
\hline & $\mathbf{1}$ & 80 & 31.7 & 36.0 & 21.6 & 29.2 & 28.3 & 38.8 & 12.5 \\
\hline \multicolumn{10}{|l|}{$0.1 M$ HF } \\
\hline \multirow{2}{*}{$\underset{0.5 M \mathrm{HNO}_{3}}{+}$} & 1 & 25 & 28.5 & 58.2 & 22.1 & 37.6 & 30.2 & 49.2 & 10.5 \\
\hline & 1 & 80 & 35.6 & 76.9 & 33.8 & 40.2 & 36.8 & 77.2 & 77.4 \\
\hline \multirow{2}{*}{$\begin{array}{c}0.5 \mathrm{MNO}_{3} \\
+\end{array}$} & $\mathbf{1}$ & 25 & 22.5 & 26.0 & 10.1 & 29.7 & 28.6 & 27.4 & 4.5 \\
\hline & 24 & 25 & 23.0 & 57.8 & 14.9 & 32.7 & 27.5 & 55.8 & 52.4 \\
\hline $0.5 M$ HAc & 1 & 80 & 20.6 & 58.2 & 15.5 & 31.1 & 26.2 & 58.8 & 75.4 \\
\hline \multirow{2}{*}{$\underset{+}{0.13 M \mathrm{H}_{2} \mathrm{O}_{2}}$} & $\mathbf{1}$ & 25 & 21.9 & 24.8 & 7.8 & 29.9 & 25.6 & 28.4 & 9.3 \\
\hline & 24 & 25 & 21.1 & 47.6 & 15.5 & 30.6 & 25.1 & 53.3 & 20.8 \\
\hline $0.5 M \mathrm{HCl}$ & 1 & 80 & 21.2 & 60.3 & 18.0 & 28.5 & 25.1 & 59.7 & 50.8 \\
\hline \multirow{3}{*}{$\mathrm{H}_{2} \mathrm{O}$} & $\mathbf{1}$ & 25 & 18.3 & 7.5 & 4.5 & 22.1 & 22.5 & 14.8 & 0.9 \\
\hline & 24 & 25 & 19.7 & 8.5 & 3.1 & 22.1 & 24.6 & 15.0 & 0.8 \\
\hline & 1 & 80 & 18.6 & 8.8 & 11.1 & 21.6 & 23.3 & 15.4 & 0.8 \\
\hline
\end{tabular}

into the lower section of the separator while it was still hot. After 20 hours of soaking, no appreciable effects were apparent, except for a marginal softening of the scale. The poor results may have been due to cooling of the solvent (we had no means for temperature maintenance) and an insufficient solventto-scale ratio.

The results of these in situ tests indicate the problems that will be encountered in an actual application. The foremost difficulty will be slow rate of dissolution because of the very low surface-tomass ratio of a thick scale layer. Note that all of the laboratory tests were conducted with finely ground scale samples in a constantly agitated solution. Furthermore, maintenance of temperature will require a separate heating system for the reagents or for the plant components. Another concern is that the amount of scale material in a layer deposited on pipe walls is large compared with the volume available to be occupied by the reagent. Repeated soakings will be necessary.

In conclusion, the laboratory measurements, conducted at near-optimum conditions, did not reveal an outstanding and fast-dissolving reagent that would be of some utility under much less favorable conditions in a plant. A combination of chemical and mechanical cleaning methods may be most effective. However, the improvement added by use of chemicals may be marginal and greatly overshadowed by their cost, corrosivity, and hazard to operating personnel. 


\section{ACKNOWLEDGMENTS}

We thank L. B. Owen for furnishing the photographs in Fig. 1, which he obtained during a 1975 study. Chemical analyses of the scales were performed by R. W. Ryon and W. J. Beiriger. 


\section{APPENDIX}

GRAPHS OF THE DISSOLUTION OF SCALES BY VARIOUS REAGENTS

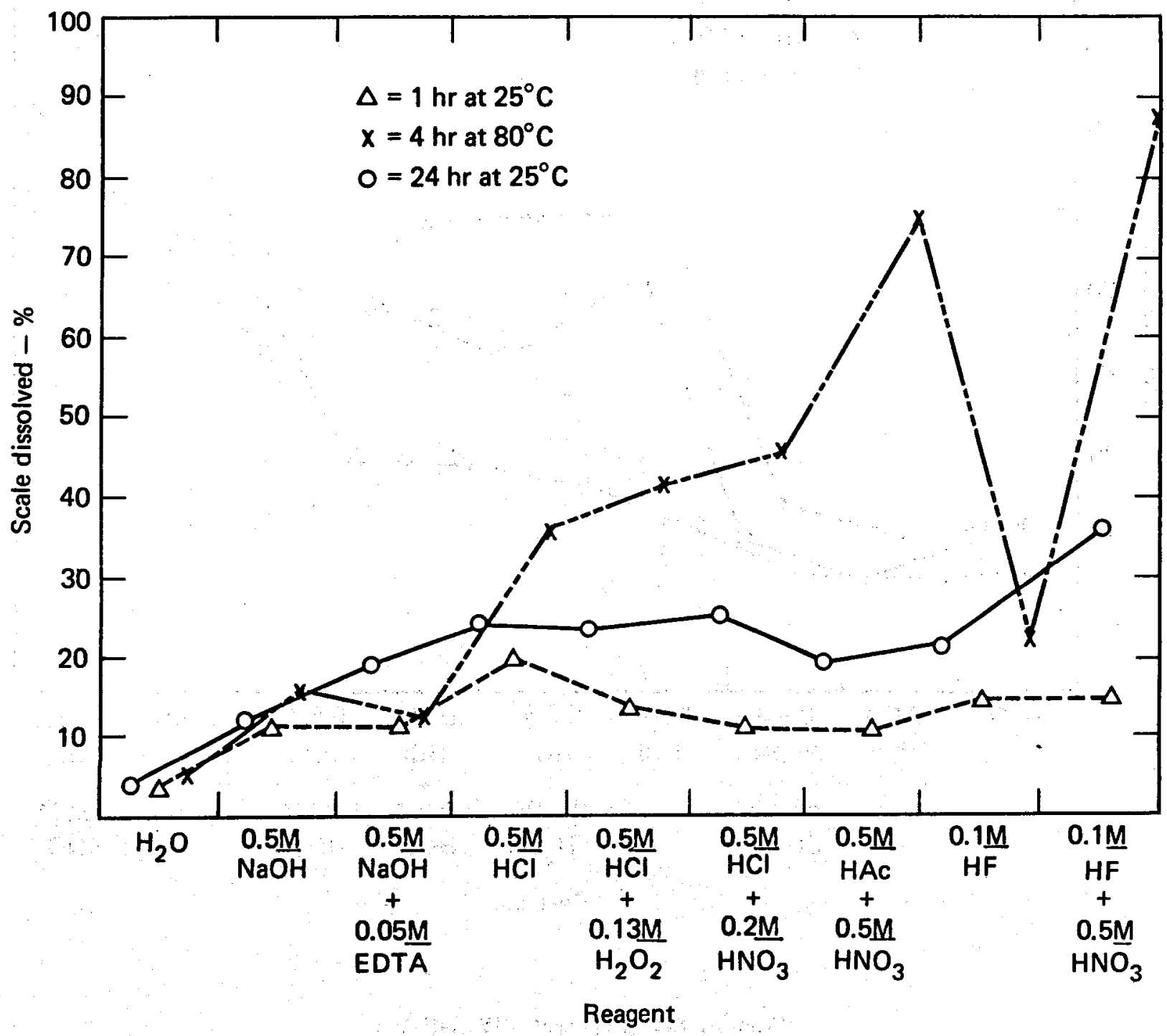

Woolsey production-line scale (W-PL)

PbS-rich 


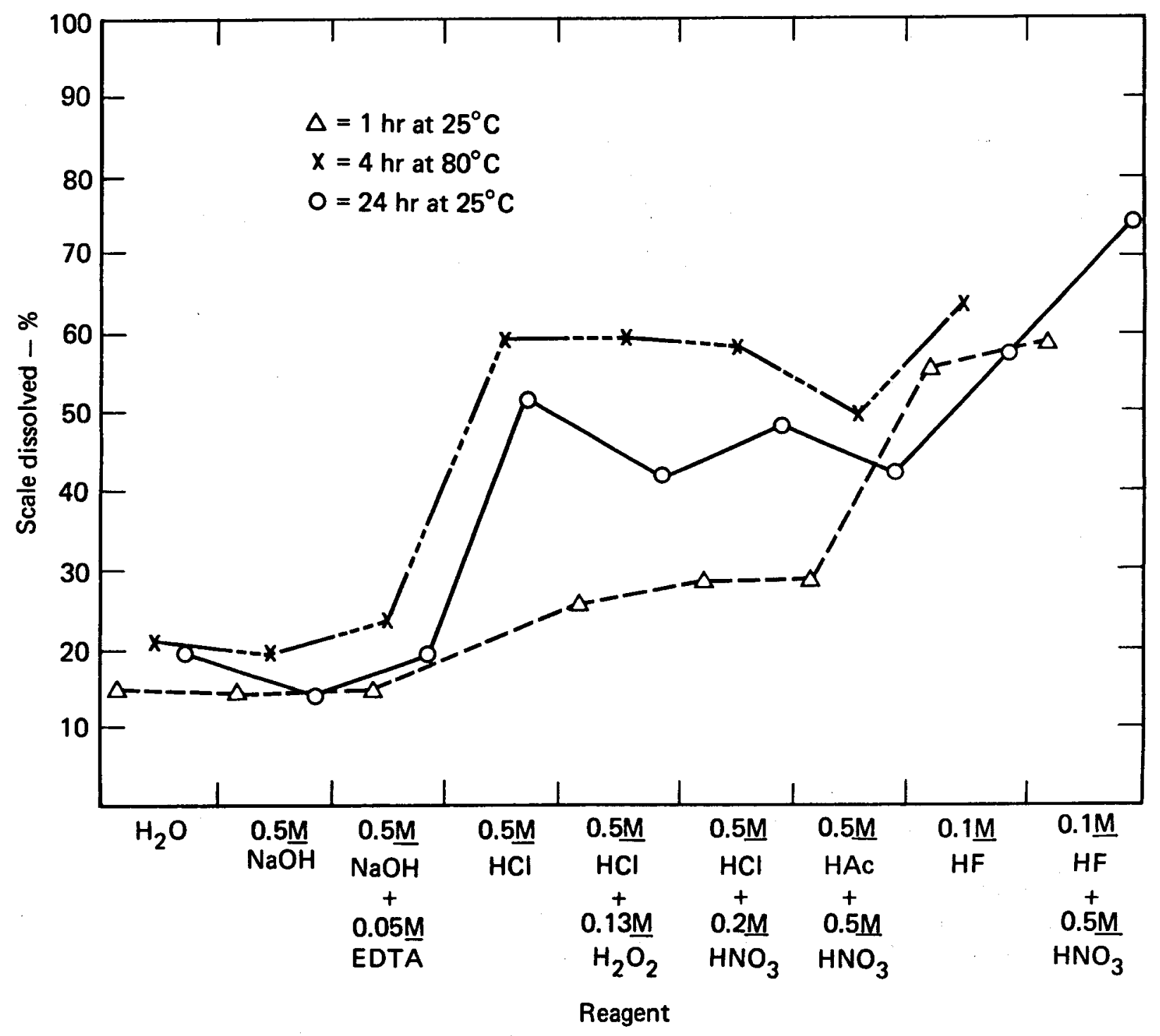

Woolsey first-stage scale (W1A-IN) $\mathrm{SiO}_{2}, \mathrm{PbS}$, and iron-rich compounds 


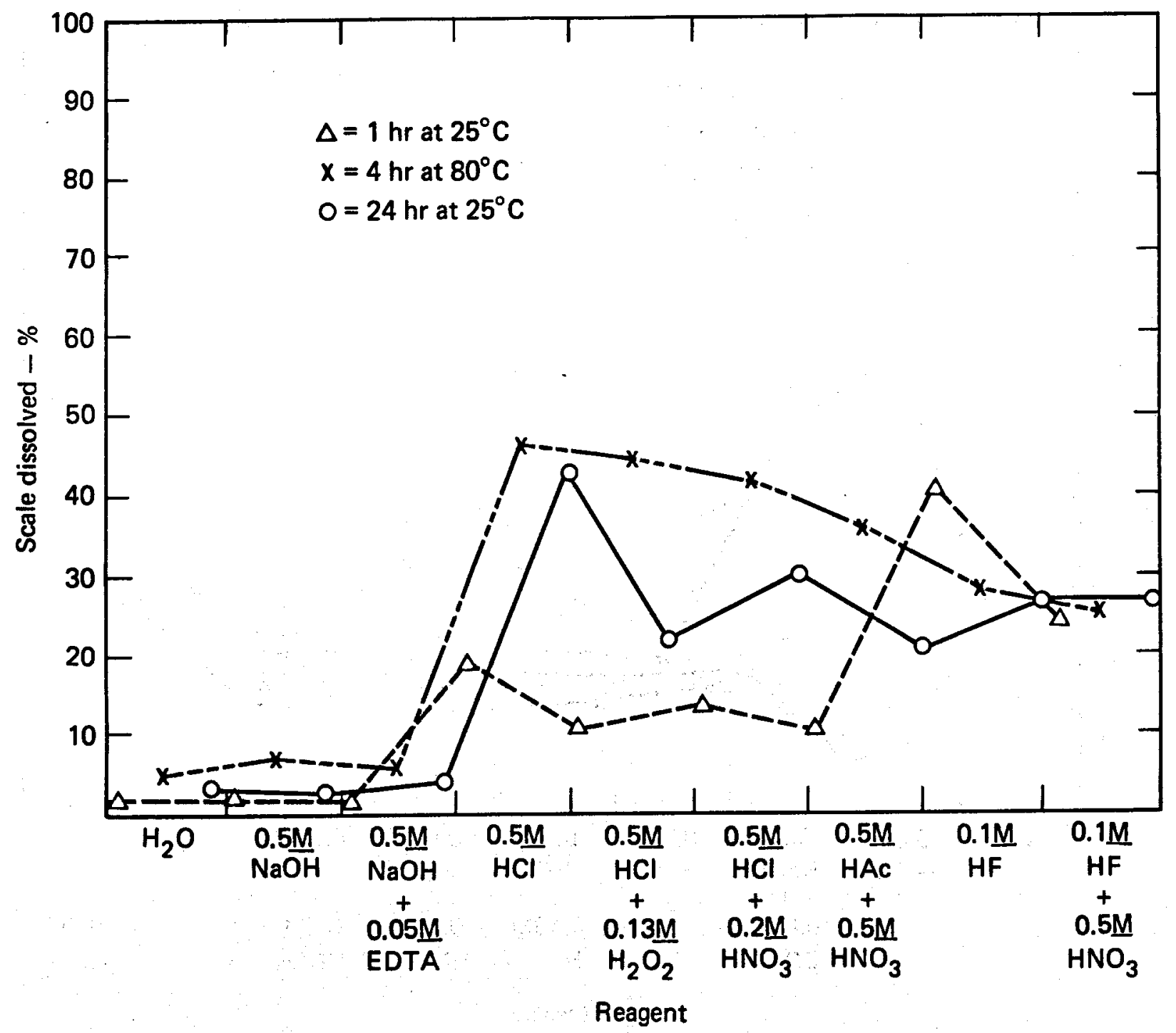

Woolsey first-stage scale (W1A-DS)

$\mathrm{SiO}_{2}, \mathrm{PbS}$, and iron-rich compounds 


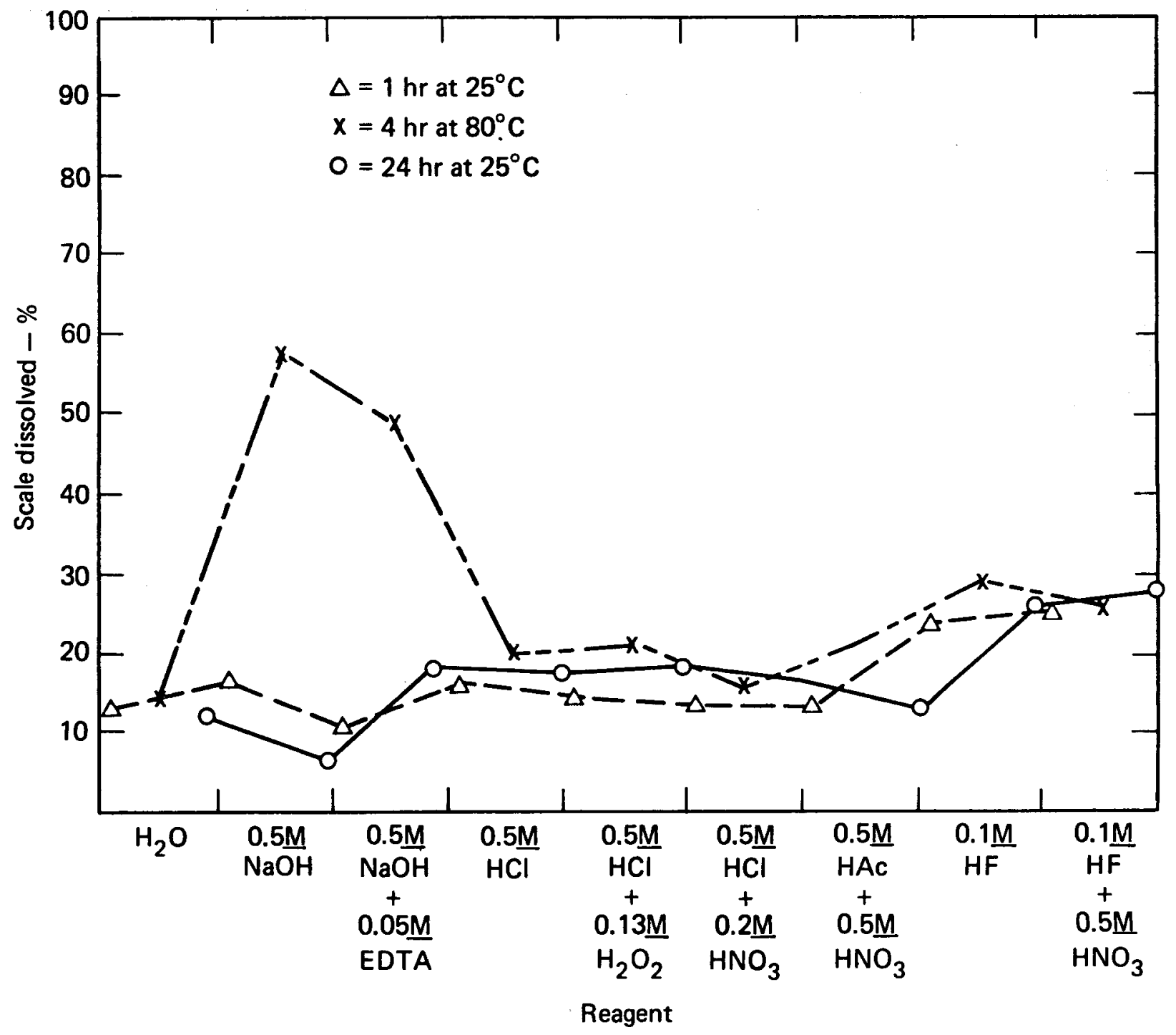

Woolsey second-stage scale (W2A-DS)

$\mathrm{SiO}_{2}$-rich 


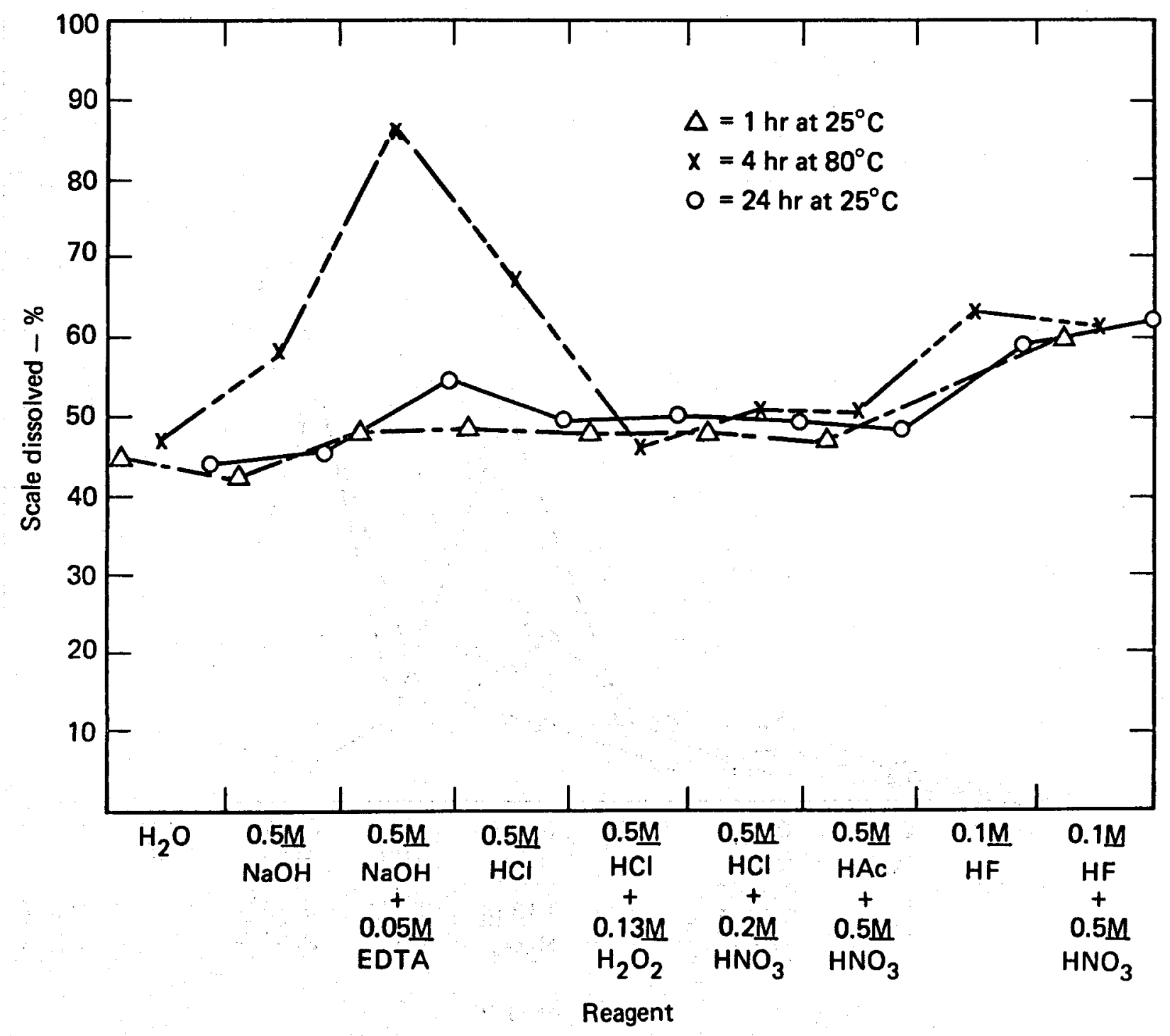

Woolsey atmospheric-receiver scale (WV15-OUT) $\mathrm{SiO}_{2}$-rich 


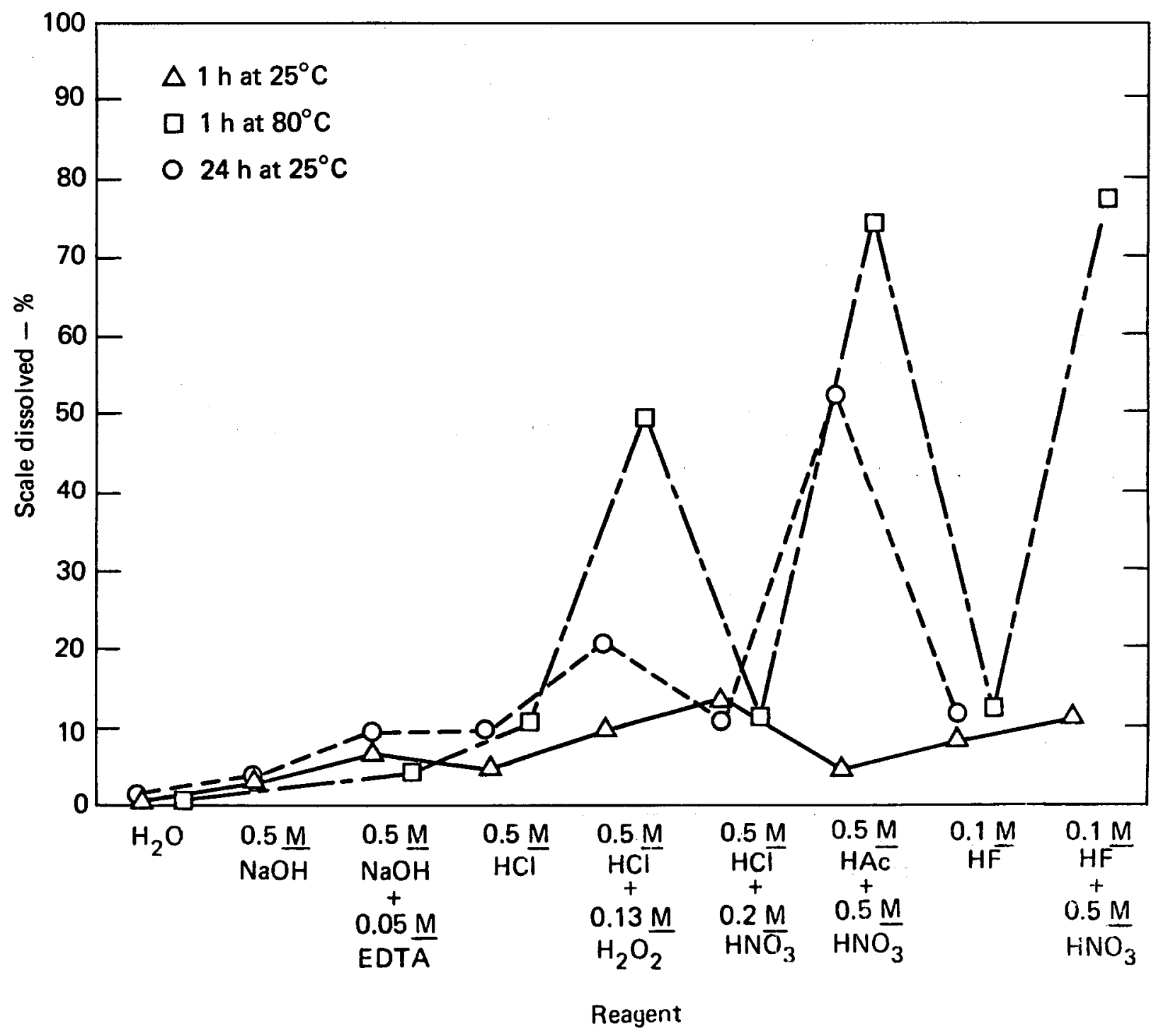

Magmamax wellhead scale

PbS-rich 


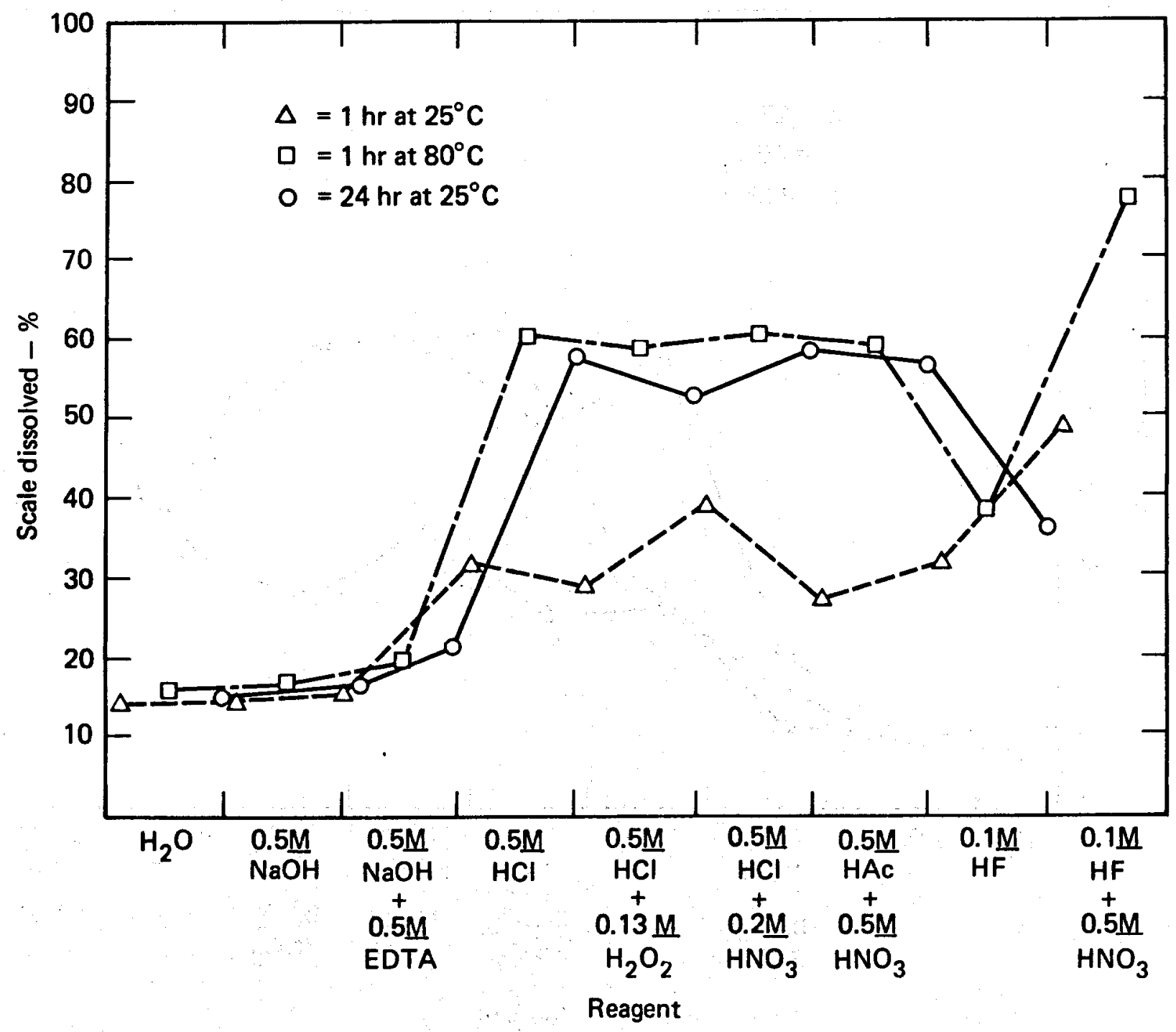

Magmamax first-stage scale (V4)

$\mathrm{SiO}_{2}, \mathrm{PbS}$, and iron-rich compounds 


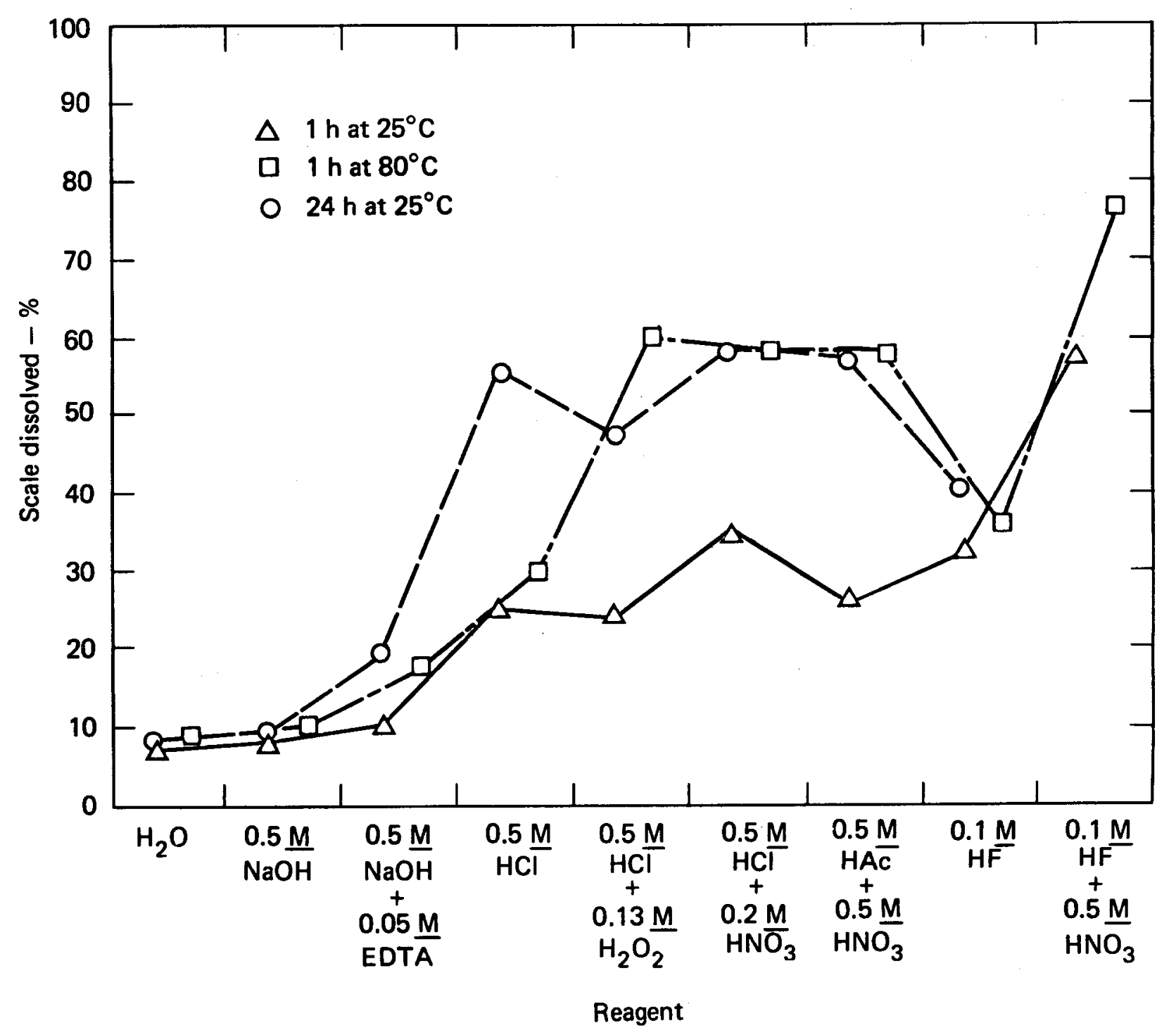

Magmamax first-stage scale (V4D)

$\mathrm{SiO}_{2}, \mathrm{PbS}$, and iron-rich compounds 


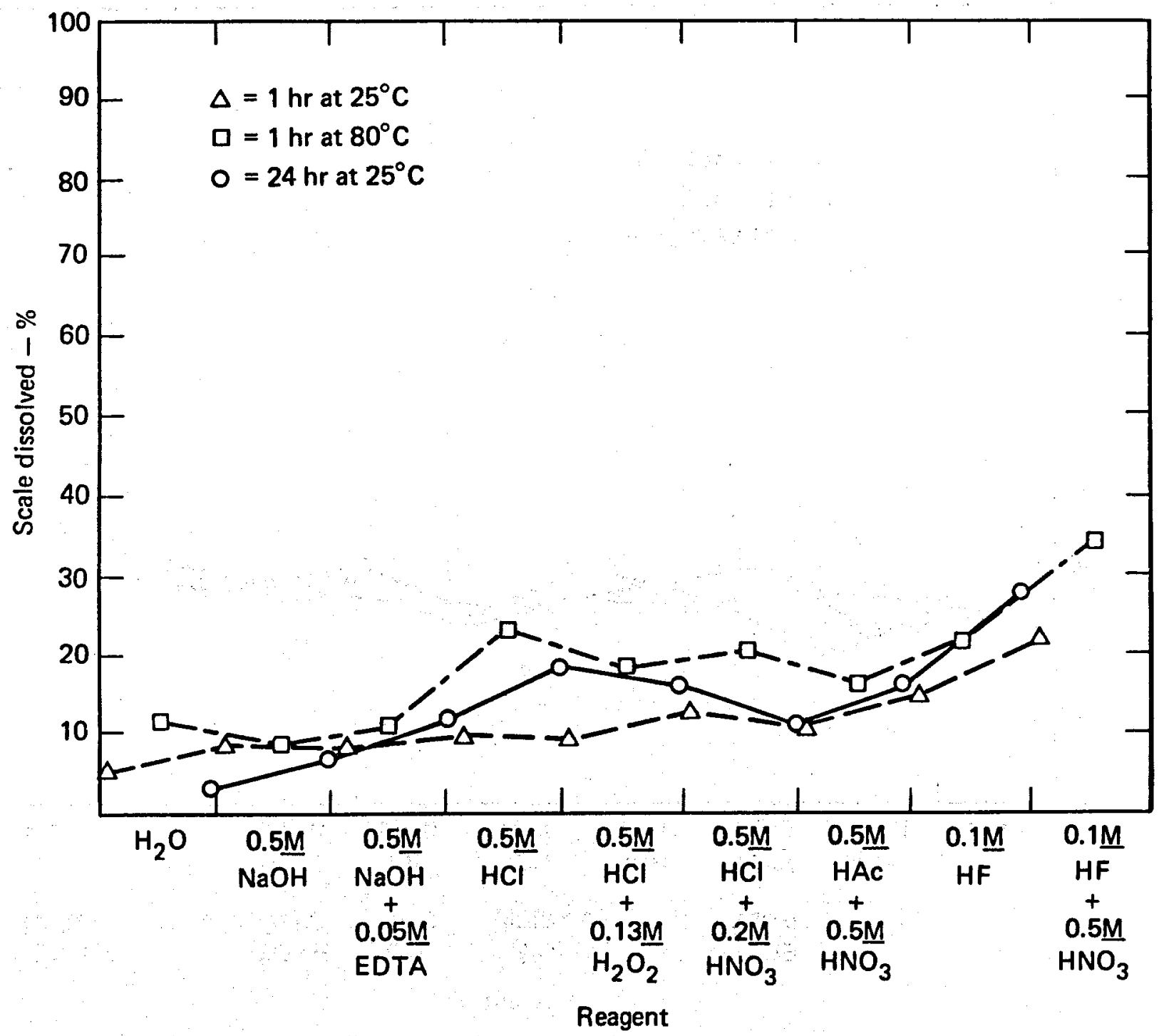

Magmamax second-stage scale (V11 TOP)

$\mathrm{SiO}_{2}$ and iron-rich compounds 


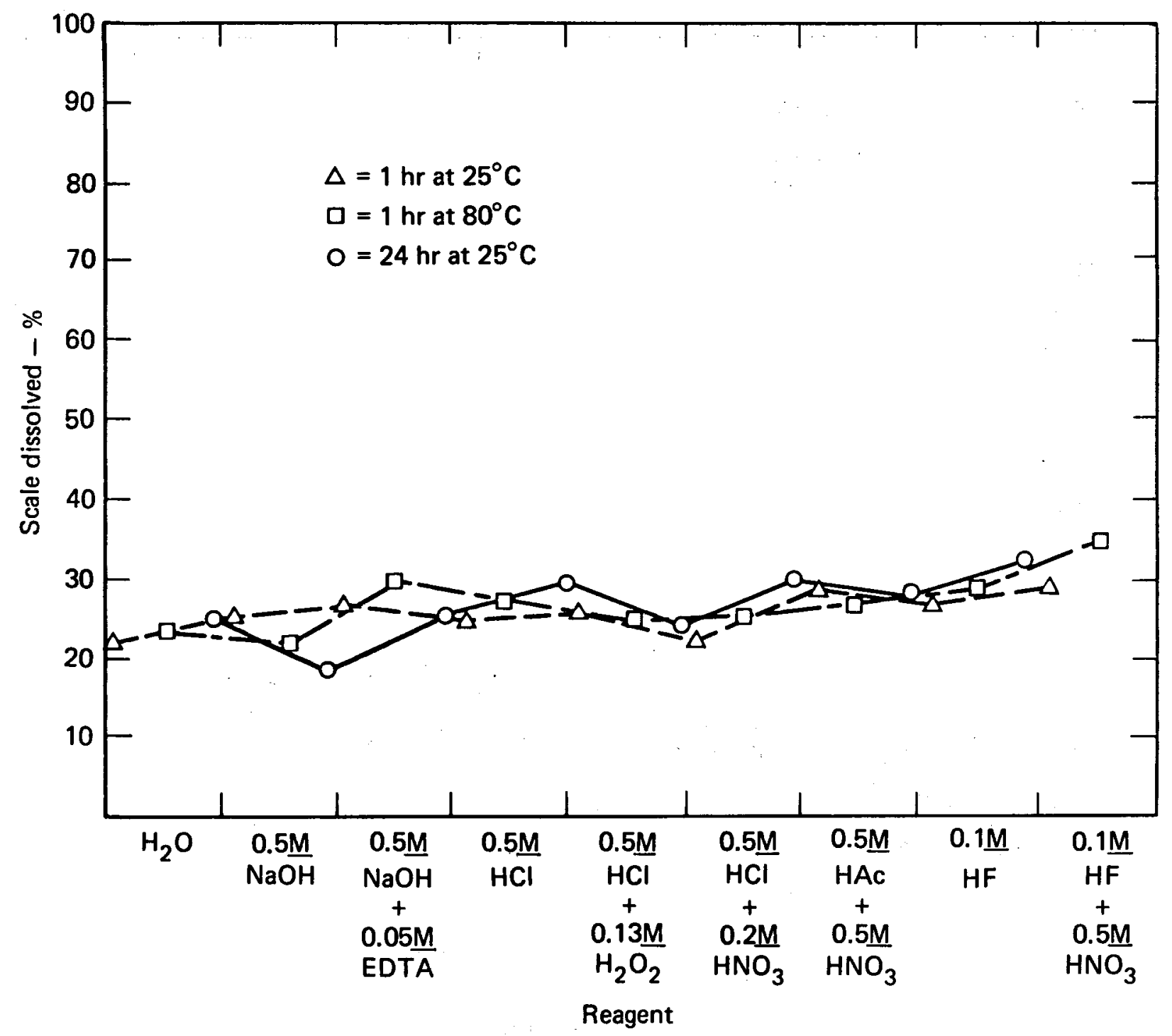

Magmamax second-stage scale (V11) $\mathrm{SiO}_{2}$-rich 


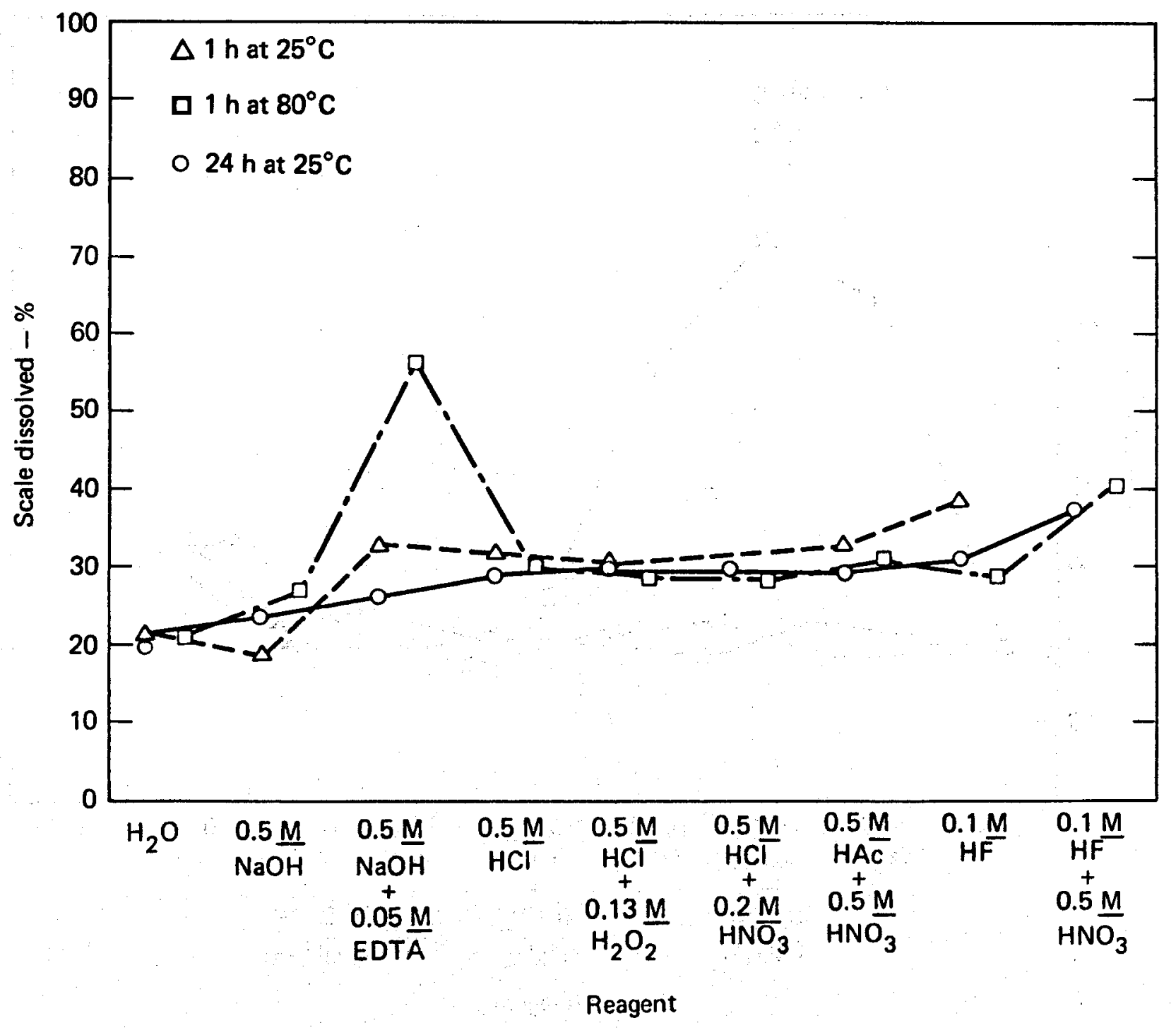

Magmamax second-stage scale (V11D)

$\mathrm{SiO}_{2 \text {-rich }}$ 


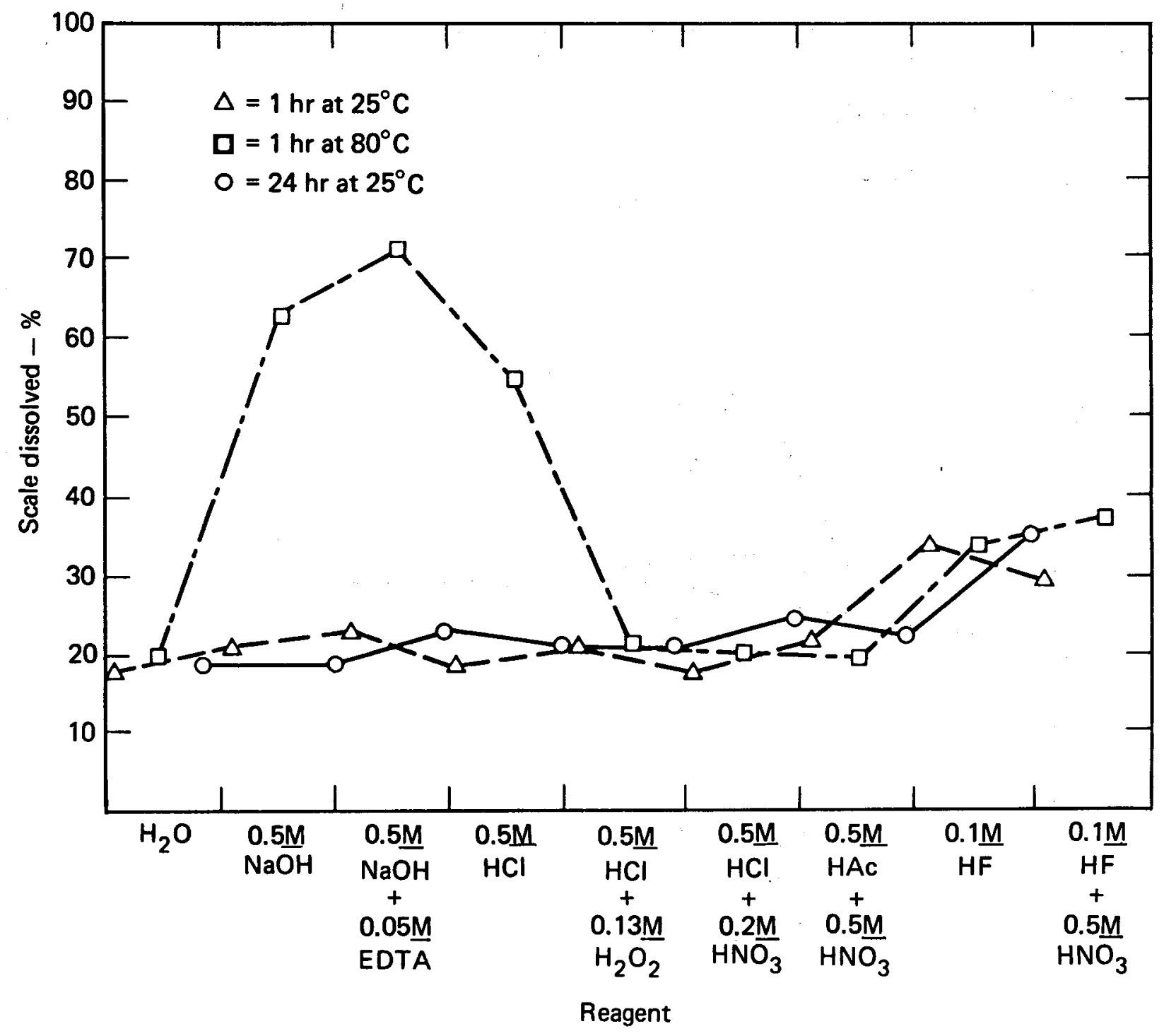

Magmamax atmospheric-receiver scale (V15D) $\mathrm{SiO}_{2}$-rich 